\title{
Graphitic nanomaterials from biogas-derived carbon nanofibers
}

\author{
N. Cuesta ${ }^{\text {a }}$, I. Cameán ${ }^{\text {a }}$, A. Ramos ${ }^{\text {a }}$, S. de Llobet ${ }^{\text {b }}$, A. B. Garcia ${ }^{\text {a * * }}$ \\ ${ }^{a}$ Instituto Nacional del Carbón, CSIC, Francisco Pintado Fe 26, 33011 Oviedo, Spain \\ ${ }^{b}$ Instituto de Carboquímica, CSIC, Miguel Luesma Castán 4, 50018 Zaragoza, Spain
}

\begin{abstract}
Carbon nanofibers with different microstructure and elemental composition that were produced in the catalytic decomposition of synthetic biogas mixtures, in a rotary-bed reactor using nickel and nickel-cobalt catalysts at $600{ }^{\circ} \mathrm{C}$ and $700{ }^{\circ} \mathrm{C}$, were heat treated in the temperature interval 2600$2800{ }^{\circ} \mathrm{C}$ to explore their ability to graphitize. The influence of treatment temperature as well as carbon nanofibers composition, particularly metallic species, on the structural and textural properties of the materials prepared is discussed. Graphitic nanomaterials with great development of the three-dimensional structure $\left(d_{002} \sim 0.3360 \mathrm{~nm}, L_{c} \sim 48 \mathrm{~nm}, L_{a} \sim>100 \mathrm{~nm}\right)$ and low porosity $\left(\mathrm{S}_{\mathrm{BET}} \sim 20 \mathrm{~m}^{2} \mathrm{~g}^{-1}\right)$ have been achieved. Because of the catalytic effect of silicon in the presence of inherent nickel and cobalt metals, more structurally ordered materials were obtained from the carbon nanofibers by adding silica. Based on the results of this work, the utilization of biogasderived carbon nanofibers for the production of synthetic nanographite to be used in different applications, such as electrode material in energy storage devices in which both high degree of graphitic order and small surface area are required, appears feasible.
\end{abstract}

Keywords: Biogas; Carbon nanofibers; High-temperature heat treatment; Graphitic nanomaterials

* Corresponding author.

E-mail: anabgs@incar.csic.es (A. B. Garcia). 


\section{Introduction}

Carbon nanofibers (CNFs) have achieved a prominent relevance in the last decade due to their excellent mechanical properties, high electrical and thermal conductivities as well as mesoporosity, making them promising materials for an extensive range of applications such as energy storage [14], composites [5], catalysts [6,7] or adsorbents [8,9], among others. CNFs are graphitic fibers made of stacks of graphene layers aligned perpendicular, tilted or parallel to the fiber axis, thus resulting in different microstructures [10]. They are mainly produced by decomposition of hydrocarbons over a transition metal or alloy as catalyst at temperatures in the range $500-1200{ }^{\circ} \mathrm{C}$. Furthermore, CNFs can be subjected to a wide variety of post-production treatments to improve their performance in several applications, such as the heat treatment at high temperature (HTT) under inert atmosphere to achieve the transformation of CNFs into graphitized CNFs (graphitization heat treatment), i.e, synthetic nanographite, which involves the growth of the graphitic three-dimensional order and the electrical conductivity accompanied by a decrease of the porosity and the surface area. Since these changes are known to improve the performance of carbon materials as anodes in lithium-ion batteries (LIBs), graphitized CNFs have been investigated for this application [10]. In this respect, graphitized stacked-cup CNFs have been successfully tested in LIBs, outperforming synthetic graphite having micrometric particle size (nowadays the anode material in the majority of the commercial LIBs), particularly in terms of battery charge-discharge rate, due to their nanometric particle size that reduces the diffusion length of the lithium ion in the electrode, thus allowing faster intercalation/de-intercalation processes [11].

In previous works carried out by our research group, fishbone CNFs that were obtained by catalytic decomposition of methane $(\mathrm{CDM})$ to simultaneously produce $\mathrm{CO}_{2}$-free hydrogen were subjected to HTT to explore their ability to graphitize [12-14]. Nickel catalysts supported on $\mathrm{SiO}_{2}$, $\mathrm{Al}_{2} \mathrm{O}_{3}, \mathrm{TiO}_{2}$ or $\mathrm{MgO}$ were used in this decomposition process, thus leading to CNFs containing different metals which have been traditionally employed as graphitization catalysts of carbon 
materials [15]. As indicated by X-ray diffraction (XRD), Raman spectroscopy and high-resolution transmission electron microscopy (TEM), graphitic nanomaterials with high degree of crystallinity were prepared from these methane-derived CNFs at temperatures above $2400{ }^{\circ} \mathrm{C}$, mainly because of the catalytic effect of the metal-containing species (namely $\mathrm{Ni}$ and $\mathrm{Si}$ ). Moreover, these materials were further applied as anodes in LIBs showing good performance in terms of specific capacity, capacity retention along cycling and cycling efficiency with values of these electrochemical parameters similar to those of the micrometric synthetic graphite which, as mentioned above, is the anode material par excellence in commercial LIBs [16].

Based on this background, it can be concluded that graphitized hydrocarbon-derived CNFs might be highly valuable carbon materials to be used in LIBs as well as other applications. However, like synthetic graphite (whose main precursor is petroleum coke, [17]), they have the drawback of being obtained from non-renewable energy sources. In contrast, biogas is a renewable energy source composed mainly of $\mathrm{CH}_{4}$ and $\mathrm{CO}_{2}$ from which electricity and heat are currently produced by its direct combustion in co-generation plants. Nevertheless, the exploitation of biogas for different applications appears as an interesting option, particularly when considering its renewable origin. In this context, the Catalytic Decomposition of Biogas (CDB) to simultaneously produce syngas (SG) with high hydrogen contents and bio-carbon nanofibers (BCNFs) has been studied in detail $[18,19]$. As CNFs, BCNFs from biogas have initially a certain degree of structural order and therefore, they are classified within graphitic carbons. In addition, depending on the catalyst used in the $\mathrm{CDB}$, they also may contain different metals which, a priori, are expected to promote their graphitization. Consequently, CNFs from biogas appear as a potential alternative precursor for the preparation of graphite-like materials to be considered.

The purpose of this work is to study the graphitization of the BCNFs produced in the catalytic decomposition of biogas. To this end, BCNFs with different microstructure and elemental composition that were obtained from synthetic biogas mixtures, in a rotary-bed reactor using nickel and nickel-cobalt catalysts under different experimental conditions, were heat treated in the 
temperature interval $2600-2800{ }^{\circ} \mathrm{C}$. The influence of treatment temperature as well as BCNFs composition, especially metallic species, on the structural and textural properties of the graphitic materials prepared is discussed.

\section{Materials and methods}

\subsection{Production and composition of BCNFs}

BCNFs were produced in a rotary-bed reactor by catalytic decomposition of biogas at a space velocity of $30 \mathrm{~L}_{\mathrm{N}} \mathrm{g}_{\mathrm{cat}}{ }^{-1} \mathrm{~h}^{-1}$. Two synthetic biogas mixtures containing only $\mathrm{CH}_{4}$ and $\mathrm{CO}_{2}$ with volume ratios (v:v) of 50:50 and 60:40 designed as BG1 and BG2 were used. Experiments were carried out at two different temperatures, 600 and $700{ }^{\circ} \mathrm{C}$. A detailed description of the experimental set up was previously reported [20]. Nickel or nickel-cobalt catalysts using $\mathrm{Al}_{2} \mathrm{O}_{3}$ as textural promoter with $\mathrm{Ni}: \mathrm{Al}$ or $\mathrm{Ni}+\mathrm{Co}: \mathrm{Al}$ molar ratio of $67: 33$ were prepared by the fusion method described in [21]. Following biogas designation, the as-produced BCNFs were denoted BCNF1 and BCNF2 together with $\mathrm{CDB}$ reaction temperature $\left(6\right.$ for $600{ }^{\circ} \mathrm{C}$ or 7 for $700{ }^{\circ} \mathrm{C}$ ), such as $\mathrm{BCNF} 2-7$ for those obtained from a $\mathrm{CH}_{4}: \mathrm{CO}_{2}$ mixture of $60: 40$, at $700{ }^{\circ} \mathrm{C}$. Moreover, to distinguish between catalysts, an asterisk was added to BCNFs produced with bimetallic Ni-Co catalyst, i.e. BCNF2-7** BCNFs with different $\mathrm{Si} /$ metal atomic ratio (1, 5 and 7) were prepared by mixing as-produced BCNFs with powder silica. The resulting as-prepared BCNFs were named accordingly by including this atomic ratio. Thus, $\mathrm{BCNF} 2-7-1$ and $\mathrm{BCNF} 2-7 *-1$ are the acronyms for as-prepared $\mathrm{BCNFs}$ with $\mathrm{Si} / \mathrm{Ni}$ and $\mathrm{Si} / \mathrm{Ni}+\mathrm{Co}$ atomic ratios of 1 , respectively. The $\mathrm{Al}$, $\mathrm{Co}$ and $\mathrm{Ni}$ contents in the asproduced BCNFs that were determined by inductive coupled plasma-optical emission spectroscopy and the calculated metal contents in the as-prepared BCNFs are reported in Table 1. 


\section{Table 1}

Metal contents of as-produced and as-prepared BCNFs (wt. \%, dry basis).

\begin{tabular}{|c|c|c|c|c|}
\hline BCNFs & $\mathrm{Al}$ & $\mathrm{Ni}$ & Co & $\mathrm{Si}$ \\
\hline BCNF1-6 ${ }^{\mathrm{a}}$ & 1.47 & 5.11 & & \\
\hline BCNF1-6-1 ${ }^{b}$ & 1.40 & 4.86 & & 2.31 \\
\hline BCNF1-6-5 & 1.17 & 4.05 & & 9.67 \\
\hline BCNF1-6-7 ${ }^{\mathrm{b}}$ & 1.08 & 3.74 & & 12.53 \\
\hline BCNF1- $7^{\mathrm{a}}$ & 2.01 & 6.80 & & \\
\hline BCNF1-7-1 ${ }^{b}$ & 1.88 & 6.36 & & 3.05 \\
\hline BCNF1-7- $5^{\mathrm{b}}$ & 1.49 & 5.04 & & 12.07 \\
\hline $\mathrm{BCNF} 1-7-7^{\mathrm{b}}$ & 1.35 & 4.57 & & 15.33 \\
\hline BCNF2- $6^{\mathrm{a}}$ & 1.07 & 3.83 & & \\
\hline BCNF2-6-1 ${ }^{\mathrm{b}}$ & 1.38 & 3.57 & & 1.71 \\
\hline BCNF2-6-5 & 1.20 & 3.11 & & 7.44 \\
\hline BCNF2-6-7 & 1.13 & 2.92 & & 9.79 \\
\hline BCNF2-7 $7^{\mathrm{a}}$ & 1.43 & 3.70 & & \\
\hline BCNF2-7-1 ${ }^{b}$ & 1.03 & 3.69 & & 1.76 \\
\hline BCNF2-7-5 & 0.89 & 3.20 & & 7.66 \\
\hline BCNF2-7-7 & 0.84 & 3.01 & & 10.06 \\
\hline $\mathrm{BCNF} 2-7 *^{\mathrm{a}}$ & 1.88 & 4.18 & 4.17 & \\
\hline $\mathrm{BCNF} 2-7 *-1^{\mathrm{b}}$ & 1.75 & 3.59 & 3.88 & 3.25 \\
\hline BCNF2-7*-5 & 1.37 & 3.04 & 3.04 & 12.70 \\
\hline BCNF2-7*-7 & 1.23 & 2.75 & 2.74 & 16.04 \\
\hline
\end{tabular}

${ }^{a}$ As-produced BCNFs: determined.

${ }^{\mathrm{b}}$ As-prepared BCNFs with atomic $\mathrm{Si} /$ metal $\left(\mathrm{Ni}\right.$ or $\left.\mathrm{Ni}+\mathrm{Co}^{*}\right)$ of 1,5 or 7 : calculated.

\subsection{Heat treatments of $B C N F S$}

The BCNFs were heat treated in the temperature interval of $2600-2800{ }^{\circ} \mathrm{C}$ for $1 \mathrm{~h}$ in an $\operatorname{argon}$ flow using a graphite electrical furnace. The heating rates were $25^{\circ} \mathrm{C} \mathrm{min}{ }^{-1}$ from room temperature to $1000{ }^{\circ} \mathrm{C}, 20{ }^{\circ} \mathrm{C} \min ^{-1}$ in the range $1000-2000{ }^{\circ} \mathrm{C}$ and $10{ }^{\circ} \mathrm{C} \min ^{-1}$ from $2000{ }^{\circ} \mathrm{C}$ to the prescribed temperature. The graphitic materials thus prepared were named by adding a suffix with the treatment temperature in the BCNFs designation, such as BCNF2-7/2600 (from as-produced BCNF2-7) or BCNF2-7*-7/2800 (from as-prepared BCNF2-7*-7). 
The diffractograms were recorded in a Bruker D8 powder diffractometer equipped with a Göbel mirror in the incident beam and a parallel-slits analyzer in the diffracted beam. Diffraction data were collected by step scanning with a step size of $0.02^{\circ} 2 \theta$ and scan step of 3 s. For each sample, three diffractograms were obtained, using a representative batch of sample for each run. The interlayer spacing, $d_{002}$, was determined from the position of the (002) peak by applying Bragg's equation. The crystallite sizes, along c, $L_{c}$, and a, $L_{a}$, axes were calculated from (002) and (10) peaks, respectively, using the Scherrer formula, with values of $\mathrm{K}=0.9$ for $L_{c}$ and $\mathrm{K}=1.84$ for $L_{a}$ [22]. The broadening of diffraction peaks due to instrumental factors was corrected with the use of an internal silicon standard. Standard errors of XRD parameters are $<3 \%$ and $<5 \%$ of the reported values for $L_{c}$ and $L_{a}$, respectively; the interlayer spacing values are more precise, with standard errors of $<0.06 \%$. These parameters are used to evaluate the degree of structural order of the materials [23].

Raman spectra were obtained in a Raman microspectrometer HR800 Jobin Yvon Horiba using the green line of an argon laser $(\lambda=532 \mathrm{~nm})$ as an excitation source and was equipped with a charge-coupled device (CCD) camera. The 100x objective lens of an Olympus M Plan optical microscope was used both to focus the laser beam (at a power of $\sim 25 \mathrm{~mW}$ ) and collect the scattered radiation. Extended scans from 1700 to $1250 \mathrm{~cm}^{-1}$ were carried out to obtain the Raman spectra of the samples, with typical exposure times of $30 \mathrm{~s}$. To assess differences within samples, at least 21 measurements were performed on different particles of each individual sample. The Raman spectra were satisfactorily deconvoluted into three different bands, namely D, G, and D' (for an example, see Fig. S1 in Supporting Information). The intensity $I$ (integrated area) and the width $W$ of the Raman bands was measured using a mixed Gaussian-Lorentzian curve-fitting procedure. The relative intensity of the Raman D-band $\left(I_{D} / I_{t}\right.$ with $\left.I_{t}=I_{G}+I_{D}+I_{D}\right)$ was calculated with standard 
errors lower than $5 \%$. In addition to provide information about the structural order of the graphitic materials prepared, $I_{D} / I_{t}$ has also been used to estimate the degree of orientation of the crystallites since it has been proved that orientation has a large influence on the D-Raman band [23].

The textural properties of the materials were derived from the nitrogen adsorption-desorption isotherms performed at $-196^{\circ} \mathrm{C}$ in a Micromeritics ASAP 2420 apparatus. Before measurements, the samples were outgassed overnight by heating at $250{ }^{\circ} \mathrm{C}$ under vacuum. Specific surface areas $\left(\mathrm{S}_{\mathrm{BET}}\right)$ were calculated using the Brunauer-Emmett-Teller (BET) method, taking $16.2 \mathrm{~nm}^{2}$ for the cross-sectional area of the nitrogen-adsorbed molecule. Total pore volumes $\left(\mathrm{V}_{\mathrm{t}}\right)$ were determined by the amount of $\mathrm{N}_{2}$ adsorbed at $p / p^{o}=0.97$. Mesopore $(2-50 \mathrm{~nm})$ and micropore volumes were calculated from the cumulative pore size distributions obtained by applying Density Functional Theory (DFT) methods to the $\mathrm{N}_{2}$ adsorption isotherm $\left(p / p^{o}=0.97\right)$.

TEM analysis was carried out on a JEOL-2000 FXII microscope operating at $200 \mathrm{kV}$. Firstly, samples were dispersed in ethanol and a drop of solution was deposited on a copper grid, previously covered by a holey amorphous carbon film. Examination of the sample was focused on parts of the samples lying across the holes to obtain information free of the contribution of the amorphous supporting carbon film.

\section{Results and discussion}

\subsection{Influence of BCNFs treatment temperature}

The interlayer distance, $d_{002}$, and the mean crystallite sizes along c and a axes, $L_{c}$ and $L_{a}$, of the as-produced BCNFs (BCNF1-6, BCNF1-7, BCNF2-6, BCNF2-7, BCNF2-7*) and those of the materials prepared from them at $2600{ }^{\circ} \mathrm{C}$ and $2800{ }^{\circ} \mathrm{C}$ are reported in Table 2. The Raman structural parameters, width of the $\mathrm{G}$ band, $W_{G}$, and relative intensity of the $\mathrm{D}$ band, $\mathrm{I}_{\mathrm{D}} / \mathrm{I}_{\mathrm{t}}$, are also included in this table. According to XRD parameters, as-produced BCNFs already have a certain degree of 
structural order with $d_{002}$ values $<0.344 \mathrm{~nm}$, therefore they can be classified within graphitic materials [24]. In general terms, the HTT of BCNFs clearly leads to materials with higher development of the graphite-like structure as shown by the decrease of $d_{002}$, and the growth of the crystallite sizes, particularly along the basal plane $\left(L_{a}\right)$, which can be attributed to the preferential coalescence of adjacent crystallites in this direction, or to the coexistence of this lateral coalescence with a vegetative process (growth in-plane by incorporation of disordered carbon) [25]. Unlike $L_{a}$, the growth of $L_{c}$ just occurs by coalescence along the c-axis.

\section{Table 2}

Interlayer distance $d_{002}$, crystallite sizes $L_{c}$ and $L_{a}$, G-Raman band width $W_{G}$ and D-Raman band relative intensity $I_{D} / I_{t}$ of as-produced BCNFs and graphitic materials prepared by HTT.

\begin{tabular}{lccccc}
\hline Material & $\begin{array}{c}d_{002} \\
(\mathrm{~nm})\end{array}$ & $\begin{array}{c}L_{c} \\
(\mathrm{~nm})\end{array}$ & $\begin{array}{c}L_{a} \\
(\mathrm{~nm})\end{array}$ & $\begin{array}{c}W_{G} \\
\left(\mathrm{~cm}^{-1}\right)\end{array}$ & $\begin{array}{c}I_{D} / I_{t} \\
(\%)\end{array}$ \\
\hline BCNF1-6 & 0.3418 & 5.9 & 17.2 & 49 & 53 \\
BCNF1-6/2600 & 0.3399 & 10.5 & 36.9 & 24 & 29 \\
BCNF1-6/2800 & 0.3398 & 10.5 & 37.7 & 25 & 24 \\
BCNF1-7 & 0.3422 & 5.9 & 15.0 & 44 & 48 \\
BCNF1-7/2600 & 0.3420 & 6.9 & 27.8 & 24 & 24 \\
BCNF1-7/2800 & 0.3417 & 7.2 & 33.8 & 22 & 23 \\
BCNF2-6 & 0.3417 & 6.0 & 15.5 & 48 & 54 \\
BCNF2-6/2600 & 0.3410 & 9.3 & 25.4 & 31 & 33 \\
BCNF2-6/2800 & 0.3407 & 9.8 & 26.5 & 27 & 29 \\
BCNF2-7 & 0.3424 & 5.7 & 13.7 & 46 & 48 \\
BCNF2-7/2600 & 0.3423 & 6.7 & 22.4 & 27 & 25 \\
BCNF2-7/2800 & 0.3420 & 7.1 & 26.4 & 27 & 24 \\
BCNF2-7* & n.d. & n.d. & n.d. & 49 & 51 \\
BCNF2-7*/2600 & 0.3430 & 6.2 & 25.7 & 29 & 29 \\
BCNF2-7*/2800 & 0.3428 & 6.4 & 30.6 & 28 & 26 \\
\hline
\end{tabular}

n.d.: not determined because of Co fluorescence with $\mathrm{Cu}$ X-ray radiation source.

The structural evolution of the BCNFs during HTT can be better appreciated in Fig. 1, in which as an example, the XRD patterns of as-produced BCNF1-7 and of the graphitic materials prepared, BCNF1-7/2600 and BCNF1-7/2800, are displayed. The peaks corresponding to nickel metal from the catalyst at $\sim 45^{\circ}, \sim 52^{\circ}$, and $\sim 76^{\circ}$ in the pattern of BCNF1-7 were not observed after heat 
treatment. Moreover, the $(002)$ peak at $\sim 26^{\circ}$ became more intense and narrower. This fact together with the presence in the profiles of BCNF1-7/2600 and BCNF1-7/2800 materials of the (10) band in the range $42^{\circ}-45^{\circ}$ and, (004), (110) and (112) peaks at $\sim 55^{\circ}, \sim 77^{\circ}$, and $\sim 84^{\circ}$ are associated with the development of a three-dimensional crystalline graphite-type structure.

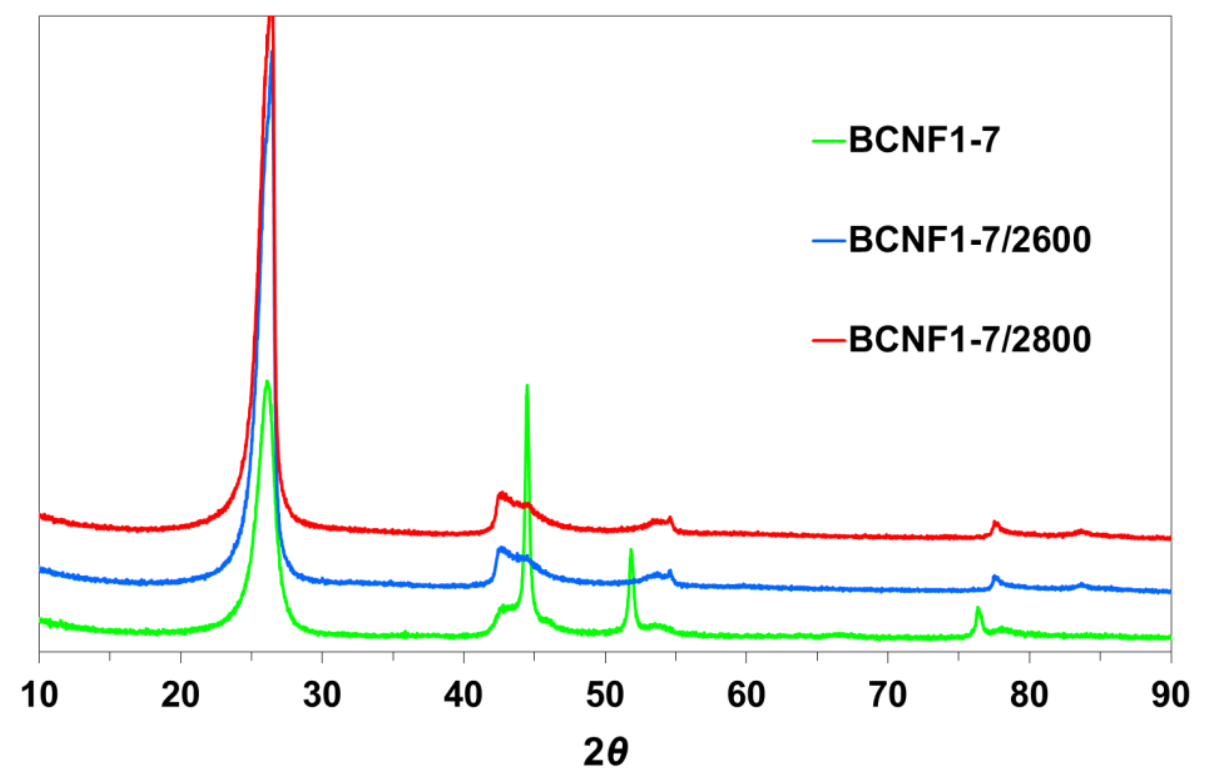

Fig. 1. XRD profiles of BCNF1-7/2600 and BCNF1-7/2800 graphitic materials, and as-produced BCNF1-7.

Raman data of materials are consistent with the above discussed XRD results. The first-order Raman spectra $\left(1000-2000 \mathrm{~cm}^{-1}\right)$ have three bands: a prominent G-band at $\sim 1580 \mathrm{~cm}^{-1}$, characteristic of graphite, a less intense D-band at $\sim 1350 \mathrm{~cm}^{-1}$, assigned to disorder or structural defects, and a D'-band at $\sim 1620 \mathrm{~cm}^{-1}$, close to $\mathrm{G}$ band (as a shoulder) which in carbons has been ascribed to edge planes [26]. The spectra of BCNF2-6/2600 and BCNF2-6/2800 materials are shown in Fig. 2. For comparison, that of as-produced BCNF2-6 precursor is also included. As seen, the intensity of the D band decreases relative to that of the G band with HTT, indicating the removal of structural defects, in other words, the improvement of the degree of structural order. Moreover, a narrowing of the $\mathrm{G}$ band is observed that is related to an increase of the size and/or orientation of the graphitic domains [23,27,28]. These two effects are summarized in the decrease 
of the relative intensity of the D-band $\left(I_{D} / I_{t}\right)$ (Table 2). Thus for example, $I_{D} / I_{t}$ values of $54 \%, 33 \%$ and $29 \%$ have been determined for BCNF2-6 (as-produced BCNFs), BCNF2-6/2600 and BCNF26/2800, respectively.

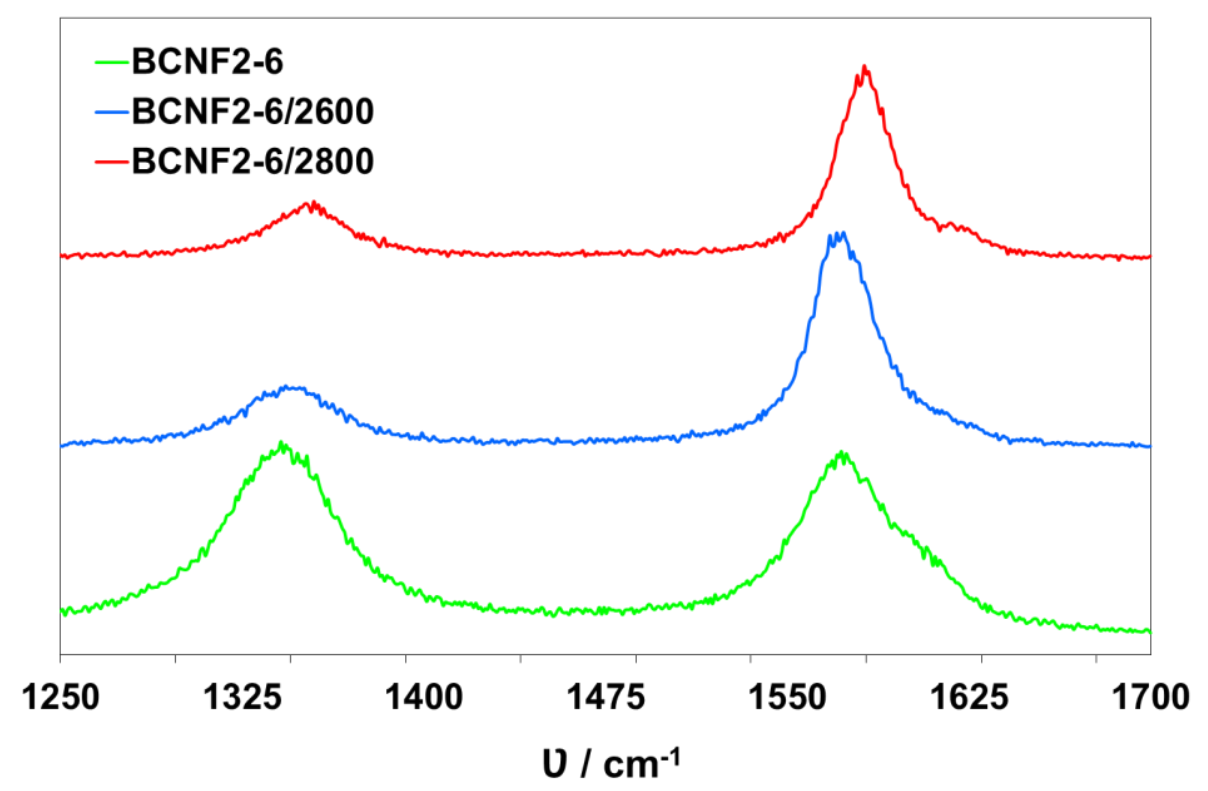

Fig. 2. First-order Raman spectra of BCNF2-6/2600 and BCNF2-6/2800 graphitic materials, and asproduced BCNF2-6.

The textural parameters of both graphitic materials prepared and as-produced BCNFs appear in Table 3. The BET surface areas of BCNFs are in the range $80-113 \mathrm{~m}^{2} \mathrm{~g}^{-1}$, and the $\mathrm{V}_{\mathrm{t}}$ in the interval $0.240-0.392 \mathrm{~cm}^{3} \mathrm{~g}^{-1}$. The porosity is mainly due to the presence of mesopores although there are a few micropores as well. The mesopores are formed by the hollow space in the nanofiber interior and in their interlacing, whereas the micropores are created because of defects on the surface of the filaments [29]. The HTT of the BCNFs leads to a substantial decrease of the surface area and porosity, i.e. $\mathrm{S}_{\mathrm{BET}}$ of BCNF1-6 decreased by 2.5 times after heat treatment at $2800{ }^{\circ} \mathrm{C}$. Even so, as expected from their nanometric nature and morphology, the surface area/porosity of the graphitic materials prepared is still larger than that of micrometric graphite and other graphite-like materials obtained from different precursors $[16,30,31]$. 


\section{Table 3}

Textural parameters of as-produced BCNFs and graphitic materials prepared by HTT.

\begin{tabular}{lcccc}
\hline Materials & $\begin{array}{c}\mathrm{S}_{\mathrm{BET}} \\
\left(\mathrm{m}^{2} \mathrm{~g}^{-1}\right)^{\mathrm{a}}\end{array}$ & $\begin{array}{c}\mathrm{V}_{\mathrm{t}} \\
\left(\mathrm{cm}^{3} \mathrm{~g}^{-1}\right)^{\mathrm{b}}\end{array}$ & $\begin{array}{c}\mathrm{V}_{\mathrm{MESO}} \\
\left(\mathrm{cm}^{3} \mathrm{~g}^{-1}\right)^{\mathrm{c}}\end{array}$ & $\begin{array}{c}\mathrm{V}_{\text {MICRO }} \\
\left(\mathrm{cm}^{3} \mathrm{~g}^{-1}\right)^{\mathrm{d}}\end{array}$ \\
\hline BCNF1-6 & 96 & 0.240 & 0.171 & 0.011 \\
BCNF1-6/2600 & 39 & 0.194 & 0.156 & 0.004 \\
BCNF1-6/2800 & 38 & 0.191 & 0.157 & 0.005 \\
BCNF1-7 & 80 & 0.241 & 0.188 & 0.008 \\
BCNF1-7/2600 & 57 & 0.187 & 0.171 & 0.005 \\
BCNF1-7/2800 & 56 & 0.150 & 0.153 & 0.004 \\
BCNF2-6 & 101 & 0.240 & 0.166 & 0.012 \\
BCNF2-6/2600 & 52 & 0.190 & 0.189 & 0.007 \\
BCNF2-6/2800 & 50 & 0.173 & 0.169 & 0.007 \\
BCNF2-7 & 99 & 0.299 & 0.252 & 0.010 \\
BCNF2-7/2600 & 64 & 0.236 & 0.235 & 0.009 \\
BCNF2-7/2800 & 60 & 0.210 & 0.207 & 0.008 \\
BCNF2-7* & 113 & 0.392 & 0.333 & 0.010 \\
BCNF2-7*/2600 & 73 & 0.279 & 0.297 & 0.010 \\
BCNF2-7*/2800 & 71 & 0.284 & 0.286 & 0.010 \\
\hline
\end{tabular}

${ }^{a}$ BET surface area calculated from the $\mathrm{N}_{2}$ adsorption data.

${ }^{\mathrm{b}}$ Total $\mathrm{N}_{2}$ pore volume (at $p / p^{o}=0.976$ ).

${ }^{\mathrm{c}}$ Mesopore and ${ }^{\mathrm{d}}$ Micropore volumes obtained by DFT.

By comparing the XRD (Table 2) and textural (Table 3) parameters of the materials it is evident that the decrease of the porosity can be associated with the improvement of the structural order as a consequence of the growth of the crystallite size and the removal of the structural defects. In this context, the smallest values of the surface area $\left(38-39 \mathrm{~m}^{2} \mathrm{~g}^{-1}\right)$ were determined for those materials (BCNF1-6/2600, 2800) having larger development of graphite three-dimensional structure. In previous works, this decrease was also attributed to a partial recrystallization of carbon resulting in the removal of surface defects on the thinnest fibers as well as to the formation of loops at the edges of the graphene layers [10]. 


\subsection{Influence of BCNFs composition}

A comparative analysis of the graphitization thermal treatment results (Table 2) allows concluding that materials with higher degree of structural order are obtained from BCNFs produced by $\mathrm{CDB}$ at $600{ }^{\circ} \mathrm{C}$ regardless biogas composition. Thus, materials with $d_{002}$ of $0.3398 \mathrm{~nm}$ (BCNF16/2800), 0.3417 (BCNF1-7/2800) $0.3407 \mathrm{~nm}$ (BCNF2-6/2800), and 0.3420 nm (BCNF2-7/2800) were prepared from BCNF1-6, BCNF1-7, BCNF2-6 and BCNF2-7, respectively; the corresponding $L_{c}$ values are $\sim 11 \mathrm{~nm}, \sim 7 \mathrm{~nm}, \sim 10 \mathrm{~nm}$, and $\sim 7 \mathrm{~nm}$. In any event, these variations are not very remarkable and could be attributed to small differences among as-produced BCNFs characteristics such as microstructure and/or composition. Based on TEM observations, the BCNFs produced at $600{ }^{\circ} \mathrm{C}$ (BCNF1-6, BCNF2-6) show a fishbone microstructure, whereas a mixture of fishbone and ribbon microstructures was found in those at $700{ }^{\circ} \mathrm{C}$ (BCNF1-7 and BCNF2-7). As an example, the high-resolution TEM images of the as-produced BCNF2-6 and BCNF2-7 are shown in Fig. 3. Therefore, it seems that fishbone microstructure having much more active edge sites than ribbon type might improve the incorporation of disordered carbon (vegetative growth in-plane), thus increasing the already-existing graphene layers and therefore, somehow favouring the coalescence of the crystallites that has been proposed to be the mechanism of the crystal growth in carbons during the graphitization thermal treatment [25]. 


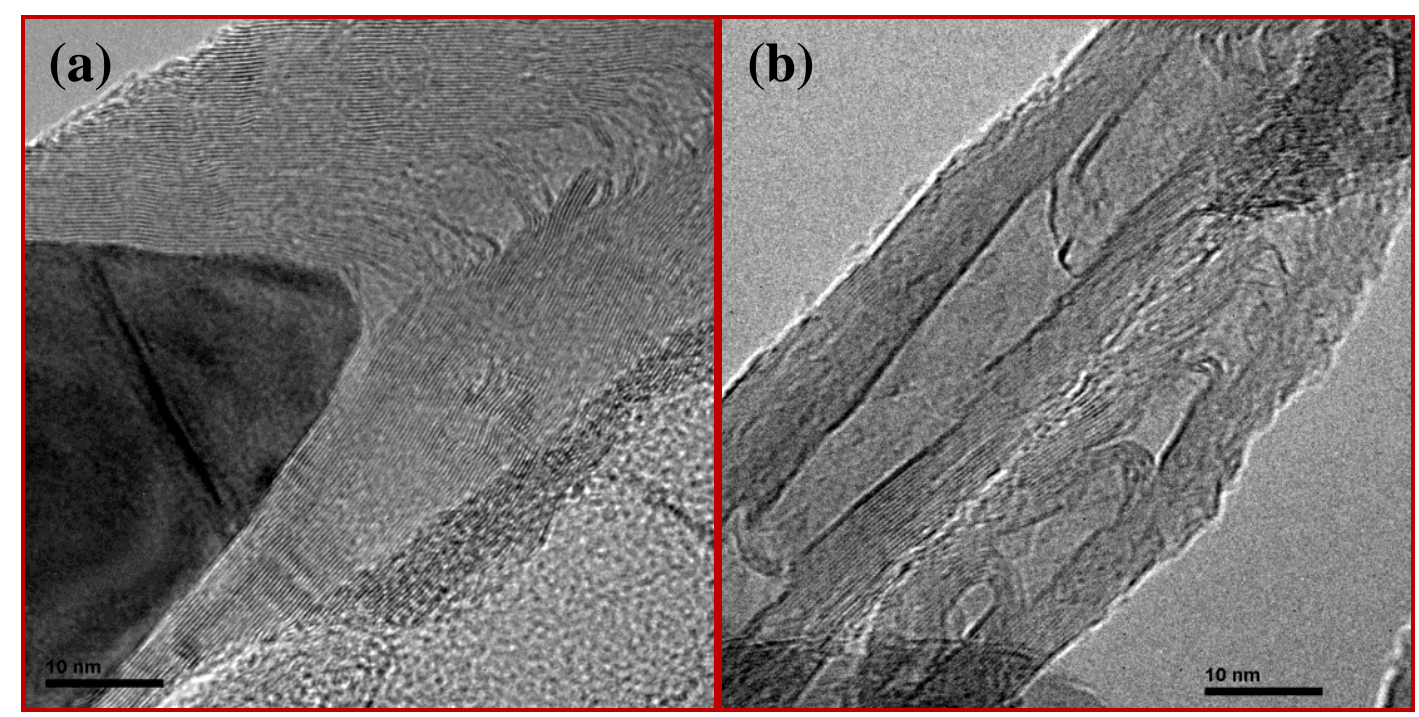

Fig. 3. TEM images of as produced (a) BCNF2-6: fishbone microstructure and (b) BCNF2-7: fishbone/ribbon mixture microstructure.

Although additional work should be done to confirm this point, it is somehow in accordance with the higher $\mathrm{H} / \mathrm{C}$ atomic ratio of BCNF1-6 (H/C 0.025) and BCNF2-6 (H/C 0.021) as regards to BCNF1-7 (H/C 0.017) and BCNF2-7 (H/C 0.013). During the HTT of graphitizable carbons, the heteroatomic (oxygen and nitrogen) and their corresponding hydrogen compounds are removed, unlocking the graphene layers and, therefore, eliminating a significant obstacle to their structural reorganization. The residual hydrogen would be located in light aromatic molecules which can act as suspensive medium for the structural basic units (BSUs), facilitating their later rearrangement to form the crystallites [32].

Finally, the influence of the inherent metallic species of the BCNFs (Al, Ni, Co) in the graphitization cannot be ruled out, particularly, considering that $\mathrm{Al}, \mathrm{Ni}$ and $\mathrm{Co}$ have been used previously as catalysts for the graphitization of different carbon materials $[15,33]$. However, no apparent improvement of the graphitic three-dimensional order of the materials prepared was observed in this work by using BCNFs with higher inherent metal content, such as for example BCNF1-7 instead of BCNF1-6 (Tables 1-3). On the contrary, as discussed above, materials with higher structural order as well as lower porosity were obtained from the latter BCNFs. Therefore, it 
appears that because of the different microstructure of the BCNFs studied, these results are inconclusive in stablishing the specific contribution of the inherent metal content to their graphitization.

The influence of the metal species on the graphitization of CNFs from CDM, all of them showing a fishbone microstructure but different metal contents, has been previously studied in our research group [12-14]. The catalytic effect of Ni metal was evident. However, the importance of this effect appeared to be governed by the presence of Si because of the synergy of these two species. In fact, a progressive improvement of the degree of structural order of the materials prepared with increasing $\mathrm{Si} / \mathrm{Ni}$ weight ratio in the CNFs was observed. The formation of a nickel silicide phase as an intermediate state which further promotes the production of silicon carbide during the graphitization process of the CNFs was inferred from the XRD analysis of the materials obtained at different temperatures. Furthermore, this carbide was found to decompose at high temperature $\left(>2400{ }^{\circ} \mathrm{C}\right)$ leading to graphitic carbon and, therefore increasing the size of alreadyforming graphene layers, in accordance with the model proposed for the catalytic graphitization of hard carbons [33]. As a result, graphitic nanofibers with crystalline parameters in the range of micrometric synthetic graphite which are currently employed in different applications were prepared in these works.

On the basis of these previous results, as-prepared BCNFs with different $\mathrm{Si} / \mathrm{metal}$ (Ni or $\mathrm{Ni}+\mathrm{Co})$ atomic ratios $(1,5,7)$ were heat treated at $2800{ }^{\circ} \mathrm{C}$ with the aim of improving the graphitization results of the as-produced BCNFs already discussed (Tables 2-3). The as-prepared BCNFs were obtained from the as-produced BCNFs by adding increasing amounts of powder silica (Table 1). A comparative analysis of the HTT results of as-produced and as-prepared BCNFs in Table 4 shows that more-ordered materials were obtained from the latter, thus inferring the catalytic effect of the metal species. Furthermore, there is a clear tendency of the materials degree of structural order to grow on increasing metal content in the BCNFs (see Fig. S2 in Supporting Information). As a result, graphitic materials with great development of the three-dimensional 
structure $\left(d_{002} \sim 0.3360 \mathrm{~nm}, L_{c} \sim 48 \mathrm{~nm}, L_{a} \sim>100 \mathrm{~nm}\right)$ have been obtained (Table 4). Moreover, the graphitic degree of the materials improves progressively as the $\mathrm{Si} / \mathrm{Ni}$ or $\mathrm{Si} / \mathrm{Ni}+\mathrm{Co}$ weight ratio in a specific BCNFs increases, in agreement with the results of previous works above cited [12-14]. For example, materials with crystallite sizes $L_{c}$ of 7, 9, 25 and $31 \mathrm{~nm}$ were prepared from BCNF2-7, BCNF2-7-1, BCNF2-7-5 and BCNF2-7-7, respectively.

\section{Table 4}

Interlayer distance $d_{002}$, crystallite sizes $L_{c}$ and $L_{a}$, D-Raman band relative intensity $I_{D} / I_{t}$, surface area $S_{\mathrm{BET}}$ and total pore volume $\mathrm{V}_{\mathrm{t}}$ of the graphitic materials obtained from as-produced and as-prepared BCNFs at $2800^{\circ} \mathrm{C}$.

\begin{tabular}{lcccccc}
\hline Material & $\begin{array}{c}d_{002} \\
(\mathrm{~nm})\end{array}$ & $\begin{array}{c}L_{c} \\
(\mathrm{~nm})\end{array}$ & $\begin{array}{c}L_{a} \\
(\mathrm{~nm})\end{array}$ & $\begin{array}{c}I_{D} / I_{t} \\
(\%)\end{array}$ & $\begin{array}{c}\mathrm{S}_{\mathrm{BET}} \\
\left(\mathrm{m}^{2} \mathrm{~g}^{-1}\right)\end{array}$ & $\begin{array}{c}\mathrm{V}_{\mathrm{t}} \\
\left(\mathrm{cm}^{3} \mathrm{~g}^{-1}\right)\end{array}$ \\
\hline BCNF1-6/2800 & 0.3398 & 10.5 & 37.7 & 24 & 38 & 0.191 \\
BCNF1-6-1/2800 & 0.3397 & 10.1 & 39.6 & 27 & 44 & 0.217 \\
BCNF1-6-5/2800 & 0.3372 & 19.8 & 50.3 & 29 & 33 & 0.161 \\
BCNF1-6-7/2800 & 0.3362 & 35.4 & 99.6 & 23 & 21 & 0.103 \\
BCNF1-7/2800 & 0.3417 & 7.2 & 33.8 & 23 & 56 & 0.150 \\
BCNF1-7-1/2800 & 0.3402 & 8.9 & 45.9 & 23 & 43 & 0.124 \\
BCNF1-7-5/2800 & 0.3361 & 40.9 & $>100.0$ & 22 & 59 & 0.169 \\
BCNF1-7-7/2800 & 0.3360 & 46.8 & $>100.0$ & 22 & 33 & 0.107 \\
BCNF2-6/2800 & 0.3407 & 9.8 & 26.5 & 29 & 50 & 0.173 \\
BCNF2-6-1/2800 & 0.3399 & 10.1 & 34.2 & 30 & 46 & 0.169 \\
BCNF2-6-5/2800 & 0.3380 & 14.9 & 51.3 & 24 & 41 & 0.152 \\
BCNF2-6-7/2800 & 0.3370 & 21.6 & 55.9 & 28 & 37 & 0.123 \\
BCNF2-7/2800 & 0.3420 & 7.1 & 26.4 & 24 & 60 & 0.210 \\
BCNF2-7-1/2800 & 0.3402 & 9.3 & 41.0 & 25 & 61 & 0.223 \\
BCNF2-7-5/2800 & 0.3367 & 25.1 & 57.3 & 24 & 50 & 0.169 \\
BCNF2-7-7/2800 & 0.3364 & 31.1 & 62.9 & 24 & 45 & 0.130 \\
BCNF2-7*/2800 & 0.3428 & 6.4 & 30.6 & 26 & 71 & 0.284 \\
BCNF2-7*-1/2800 & 0.3374 & 21.1 & 53.1 & 26 & 73 & 0.270 \\
BCNF2-7*-5/2800 & 0.3363 & 46.2 & 98.0 & 25 & 47 & 0.146 \\
BCNF2-7*-7/2800 & 0.3363 & 48.3 & $>100.0$ & 24 & 36 & 0.114 \\
\hline
\end{tabular}

The XRD patterns of these materials in Fig. 4 show clearly the progressive development of more graphitic structures as noticed by the following observations: (i) the (002), (004), (110) and 
(112) reflections at $\sim 26^{\circ}, \sim 55^{\circ}, \sim 77.5^{\circ}$, and $\sim 83.7^{\circ}$ become more intensive, narrower and symmetric, (ii) the (10) band in the range $42^{\circ}-45^{\circ}$ splits into (100) and (101) well-defined peaks and (iii) the (006) peak at $\sim 87^{\circ}$ which is typical of highly ordered graphite appears. However, materials with very different graphitic degree, i.e. BCNF1-7-7/2800 and BCNF2-6-7/2800, have been prepared from different $\mathrm{BCNF}$ containing equal $\mathrm{Si} / \mathrm{Ni}$ ratio (Table 4). Provided that the influence of the characteristics of as-produced BCNFs on their graphitization was not remarkable (Tables 1-3), this difference can only be attributed to the amount of Si in the BCNFs available to form silicide phases that were found to finally promote the production of graphite $[34,35]$. In this context, the nanographitic materials with the highest graphitic degree have been obtained from the BCNFs containing larger weight percentages of silicon (Tables 1, 4, Fig. S3 in Supporting Information).

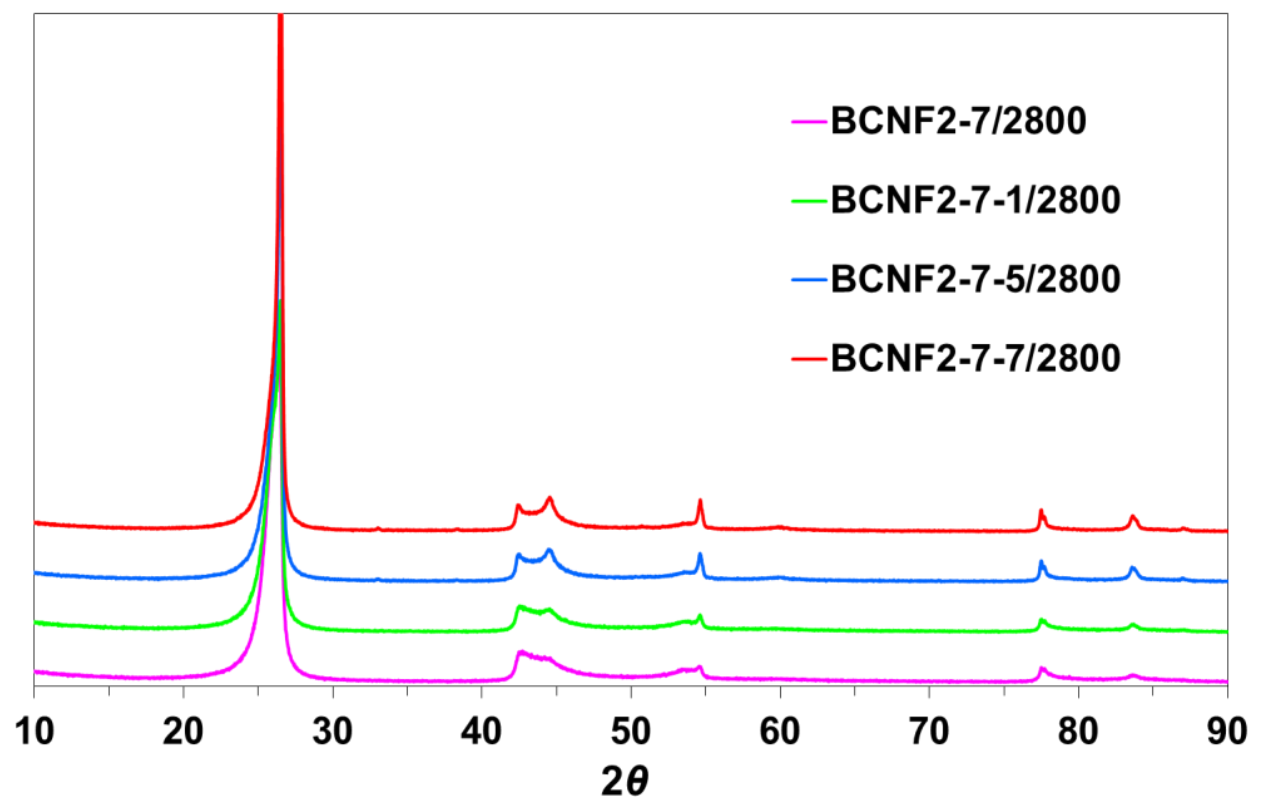

Fig. 4. XRD profiles of BCNF2-7/2800, BCNF2-7-1/2800, BCNF2-7-5/2800 and BCNF2-7-7/2800 graphitic materials.

Unlike the XRD parameters, practically no variations of the materials $\mathrm{I}_{\mathrm{D}} / \mathrm{I}_{\mathrm{t}}$ Raman ratio were observed by progressively increasing the metal content in the BCNFs (Table 4). The development of a more graphite-like structure is associated with the increase of the G-band (after graphite) and 
the decrease of the D-band (after defects) intensities of the Raman spectrum [23], therefore a decrease of this ratio was expected to occur. The formation of loops between adjacent active edge planes on the graphene layers of the BCNFs during HTT could account for the gap in the evolution of the $I_{D} / I_{t}$ ratio with increasing structural order, as assessed by XRD, since loops are known to contribute to the D' band intensity [36], which in carbons has been ascribed to edge planes [26]. Several authors have observed the presence of loops (or multiloops) in graphitized CNFs [10].

As expected from the results of the temperature influence on the graphitization of BCNFs (Tables 2-3), the progressive improvement of the structural order of the materials by increasing metal content in the BCNFs, also involves an additional decrease of porosity. Therefore, graphitic materials with significantly lower $\mathrm{S}_{\mathrm{BET}}$ and total pore volume were obtained (Table 4), particularly from those BCNFs containing higher Si/metal atomic ratio. For example, surface area values of 71 , 73,47 and $36 \mathrm{~m}^{2} \mathrm{~g}^{-1}$ were determined for graphitic materials with increasing structural degree that have been prepared from $\mathrm{BCNFs}$ containing $\mathrm{Si} / \mathrm{Ni}+\mathrm{Co}$ atomic ratios of $0,1,5$ and 7 , respectively.

\section{Conclusions}

Graphitic nanomaterials with great development of the three-dimensional structure $\left(d_{002} \sim\right.$ $\left.0.3360 \mathrm{~nm}, L_{c} \sim 48 \mathrm{~nm}, L_{a} \sim>100 \mathrm{~nm}\right)$ and low porosity $\left(\mathrm{S}_{\mathrm{BET}} \sim 20 \mathrm{~m}^{2} \mathrm{~g}^{-1}\right)$ have been achieved by heat treatment of carbon nanofibers produced in the catalytic decomposition of synthetic biogas. Specifically, more structurally ordered materials were obtained from carbon nanofibers containing silica because of the catalytic effect of silicon in the presence of inherent nickel and cobalt metals. Furthermore, it appeared that the fishbone microstructure facilitates the graphitization of the carbon nanofibers. On the basis of these results, the utilization of biogas-derived carbon nanofibers for the production of nanometric synthetic graphite to be used in different applications, such as electrode material in energy storage devices in which both high degree of graphitic order and small surface area are required, appears feasible. 


\section{Acknowledgements}

Financial support from the Spanish Ministries of Science and Innovation (MICINN) and Economy and Competitiveness (MINECO) under Projects ENE2008-06516 and ENE201128318, respectively, is gratefully acknowledged. A. Ramos, and N. Cuesta, respectively, thank the Spanish Research Council for Scientific Research (CSIC) for a JAE-Doc contract, co-funded by the European Social Fund (ESF), and the MINECO for a Ph.D. grant (BES-2012-052711) grant to develop the work.

\section{References}

[1] Y. Li, B. Guo, L. Ji, Z. Lin, G. Xu, Y. Liang et al., Structure control and performance improvement of carbon nanofibers containing a dispersion of silicon nanoparticles for energy storage, Carbon 51 (2013) 185-194.

[2] X.-B. Cheng, Q. Zhang, H.-F. Wang, G.-L. Tian, J.-Q. Huang, H.-J. Peng et al., Nitrogendoped herringbone carbon nanofibers with large lattice spacings and abundant edges: Catalytic growth and their applications in lithium ion batteries and oxygen reduction reactions, Catal. Today 249 (2015) 244-251.

[3] M. Marella , M. Tomaselli, Synthesis of carbon nanofibers and measurements of hydrogen storage, Carbon 44 (2006) 1404-1413.

[4] L. Zeng, X. Wei, J. Wang, Y. Jiang, W. Li, Y. Yu, Flexible one-dimensional carbonselenium composite nanofibers with superior electrochemical performance for $\mathrm{Li}-\mathrm{Se} / \mathrm{Na}-\mathrm{Se}$ batteries, J. Power Sources 281 (2015) 461-469. 
[5] M.M. Rahman, M. Hosur, K.-T. Hsiao, L. Wallace, S. Jeelani, Low velocity impact properties of carbon nanofibers integrated carbon fiber/epoxy hybrid composites manufactured by OOA-VBO process, Compos. Struct. 120 (2015) 32-40.

[6] J. Kang, R. Han, J. Wang, L. Yang, G. Fan, F. Li, In situ synthesis of nickel carbidepromoted nickel/carbon nanofibers nanocomposite catalysts for catalytic applications, Chem. Eng. J. 275 ( 2015) 36-44.

[7] S. Verma, S. Kumar, E. Shawat, G.D. Nessim, S.L. Jain, Carbon nanofibers decorated with oxo-rhenium complexes: Highly efficient heterogeneous catalyst for oxidation of amines with hydrogen peroxide, J. Mol. Catal. A: Chem. 402 (2015) 46-52.

[8] N. Talreja, D. Kumar, N. Verma, Removal of hexavalent chromium from water using Fegrown carbon nanofibers containing porous carbon microbeads, J. Water Process. Eng. 3 (2014) 34-45.

[9] Y. Bai, Z.-H. Huang, F. Kang, Surface oxidation of activated electrospun carbon nanofibers and their adsorption performance for benzene, butanone and ethanol, Colloid Surface A 443 (2014) 66-71.

[10] A. Ramos, I. Cameán, A.B. García, Graphitization thermal treatment of carbon nanofibers, Carbon 59 (2013) 2-32.

[11] A. Ramos, I. Cameán, N. Cuesta, A.B. García, Graphitized stacked-cup carbon nanofibers as anode materials for lithium-ion batteries, Electrochim. Acta 146 (2014) 769-775.

[12] A.B. Garcia, I. Cameán, J.L. Pinilla, I. Suelves, M.J. Lázaro, R. Moliner, The graphitization of carbon nanofibers produced by catalytic decomposition of methane: Synergetic effect of the inherent Ni and Si, Fuel 89 (2010) 2160-2162.

[13] A.B. García, I. Caméan, I. Suelves, J.L. Pinilla, M.J. Lázaro, J.M. Palacios, R. Moliner, The graphitization of carbon nanofibers produced by catalytic decomposition of natural gas, Carbon 47 (2009) 2563-2570. 
[14] I. Cameán, A.B. García, I. Suelves, J.L. Pinilla, M.J. Lázaro, R. Moliner, J.N. Rouzaud, Influence of inherent metal species on the graphitization of methane-based carbon nanofibers, Carbon 50 (2012) 5387-5394.

[15] H. Marsh, A.P. Warburton, Catalysis of graphitization, J. Appl. Chem. 20 (1970) 133-142.

[16] I. Caméan, A.B. García, I. Suelves, M.J. Lázaro, R. Moliner, Graphitized carbon nanofibers for use as anodes in lithium-ion batteries: Importance of textural and structural properties, J. Power Sources 198 (2012) 303-307.

[17] M. Inagaki, Applications of polycrystalline grahite, in: P. Delhaès (Ed.), Graphite and precursors, Gordon and Breach, Amsterdam, 2001, pp. 179-198.

[18] J.L. Pinilla, S. de Llobet, I. Suelves, R. Utrilla, M.J. Lázaro, R. Moliner, Catalytic decomposition of methane and methane/ $\mathrm{CO}_{2}$ mixtures to produce synthesis gas and nanostructured carbonaceous material, Fuel 90 (2012) 2245-2253.

[19] S. de Llobet, J.L. Pinilla, M.J. Lázaro, R. Moliner, I. Suelves, Catalytic decomposition of biogas to produce $\mathrm{H}_{2}$-rich fuel gas and carbon nanofibers. Parametric study and characterization, Int. J. Hydrogen Energ. 37 (2012) 7067-7076.

[20] J.L. Pinilla, R. Utrilla, M.J. Lázaro, I. Suelves, R. Moliner, J.M. Palacios, A novel rotary reactor configuration for simultaneous production of hydrogen an carbon nanofibers, Int. J. Hydrogen Energ. 24 (2009) 8016-8022.

[21] I. Suelves, M.J. Lázaro, R. Moliner, Y. Echegoyen, J.M. Palacio JM, Characterization of $\mathrm{NiAl}$ and $\mathrm{NiCuAl}$ catalysts prepared by different methods for hydrogen production by thermos catalytic decomposition of methane, Catalysis Today 116 (2006) 217-280.

[22] J. Biscoe, B.E. Warren, An X-Ray study of carbon black, J. Appl. Phys. 13 (1942) 364-71.

[23] A. Cuesta, P. Dhamelincourt, J. Laureyns, A. Martinez-Alonso, J.M.D. Tascon, Comparative performance of X-ray diffraction and Raman microprobe techniques for the study of carbon materials, J. Mater. Chem. 8 (1998) 2875-2879.

[24] R.E. Franklin, The structure of graphitic carbons, Acta Crystallogr. 4 (1951) 253-261. 
[25] F.G. Emmerich, Evolution with heat treatment of crystallinity in carbons, Carbon 33 (1995) $1709-1715$.

[26] G. Katagiri, H. Ishida, A. Ashitani, Raman spectra of graphite edge planes, Carbon 26 (1998) 565-571.

[27] F. Tunistra, J.L. Koenig, Raman spectra of graphite, J. Chem. Phys. 53 (1970) 1126-1130.

[28] W. Zerda, T. Gruber, Raman studies of kinetic of graphitization of carbon blacks, Rubber Chem. Technol. 73 (2000) 289-292.

[29] G.G. Kuvshinov, I.S. Chukanov, Y.L. Krutsky, V.V. Ochkov, V.I. Zaikovskii, D.G. Kuvshinov, Changes in the properties of fibrous nanocarbons during high temperature heat treatment, Carbon 47 (2009) 215-225.

[30] I. Cameán, P. Lavela, J.L. Tirado, A.B. García, On the electrochemical performance of anthracite-based graphite materials as anodes in lithium-ion batteries, Fuel 89 (2010) 986991.

[31] I. Cameán, A.B. Garcia, Graphite materials prepared by HTT unburned carbon from coal combustion fly ashes: performance as anodes in lithium-ion batteries, J. Power Sources 196 (2011) 4816-4820.

[32] D. González, M.A. Montes-Morán, I. Suárez-Ruiz, A.B. Garcia, Structural characterization of graphite materials prepared from anthracites of different characteristics: a comparative analysis, Energ. Fuel 18 (2004) 365-70.

[33] A. Oberlin, J.P. Rouchy, Catalytic graphitization of hard carbons, Carbon 9 (1971) 39-46.

[34] J.V. Milewski, F.D. Gac, J.J. Petrovic, S.R. Skaggs, Growth of beta-silicon carbide whiskers by the VLS process, J. Mater. Sci. 20 (1985) 1160-1166.

[35] F.J. Narciso_Romero, F. Rodríguez-Reinoso, Synthesis of SiC from rice hucks catalysed by iron, cobalt and nickel, J. Mater. Sci. 31 (1996) 779-784. 
[36] K. Fujisawa, T. Hasegawa, D. Shimamoto, H. Muramatsu, Y.C. Jung, T. Hayasaki et al., Boron atoms as loop accelerator and surface stabilizer in platelet type carbon nanofibers, ChemPhysChem 11 (2010) 2345-2348. 